\title{
Treatment of patients with nonsevere and severe coronavirus disease 2019: an evidence- based guideline
}

\author{
Zhikang Ye MPharm, Bram Rochwerg MD MSc, Ying Wang MPharm, Neill K. Adhikari MD, Srinivas Murthy MD, \\ François Lamontagne MD, Robert A. Fowler MD, Haibo Qiu MD, Li Wei B Pharm, Ling Sang MD, Mark Loeb MD MSc, \\ Ning Shen MD, Minhua Huang, Zhaonan Jiang, Yaseen M. Arabi MD, Luis Enrique Colunga-Lozano MD MSc, \\ Li Jiang MD, Younsuck Koh MD, Dong Liu PhD, Fang Liu MSc, Jason Phua MRCP, Aizong Shen MSc, \\ Tianyi Huo BSc, Bin Du MD, Suodi Zhai BSc, Gordon H. Guyatt MD MSc
}

Cite as: CMAJ 2020 May 19;192:E536-45. doi: 10.1503/cmaj.200648; early-released April 29, 2020

CMAJ Podcasts: interview in English at https://soundcloud.com/cmajpodcasts/200648-guide; entrevue en français au https://soundcloud.com/cmajpodcasts/200648-guide-fre

This guideline will be updated at https://app.magicapp.org/\#/guideline/EK6WOn as new evidence becomes available.

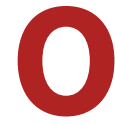

n Mar. 11, 2020, the World Health Organization (WHO) declared coronavirus disease 2019 (COVID-19) a pandemic. The worldwide spread of COVID-19 represents a profound threat to human health.

Patients with COVID-19 present primarily with fever, cough, and myalgia or fatigue, and sometimes initially with predominantly gastrointestinal symptoms. A minority of patients progress to severe pneumonia, and about $15 \%$ of these patients to critical illness characterized by acute respiratory distress syndrome (ARDS), which is associated with mortality of about $50 \% .^{1-3}$

The enormity of the adverse health consequences of COVID-19 has understandably left clinicians and patients eager for interventions that can decrease progression, prevent mortality and speed recovery. This eagerness has perhaps contributed to overly sanguine assessments from experts, regulatory authorities and prominent politicians regarding the potential benefits of treatments, with underappreciation of potential harms. ${ }^{4,5}$

Use of medication without established effectiveness can undermine public trust, result in unnecessary harm, compromise investigations that might provide definitive answers and divert resources from truly beneficial interventions. Evidencebased guidelines for treatment of patients with COVID-19 provide one strategy for avoiding overuse of highly touted but unestablished therapies.

Therefore, we have developed an evidence-based guideline that focuses on both patients with nonsevere and severe COVID19 and, for use of corticosteroids, patients with ARDS. Our guideline process followed standards of trustworthy guidelines, ${ }^{6}$

\section{KEY POINTS}

- The available evidence for treatment of coronavirus disease 2019 (COVID-19) is either indirect (from studies of influenza, severe acute respiratory syndrome and Middle East respiratory syndrome) or from several observational studies and randomized controlled trials in patients with COVID-19, which are limited in sample size and rigour, permitting only weak recommendations.

- Given the inevitable adverse effects of interventions, the guideline panel (which included 2 patient partners) inferred that most informed patients would decline treatment when only very low-quality evidence of benefits - and, thus, very large uncertainty - is available.

- The panel made only 1 weak recommendation in favour of treatment: use of corticosteroids in patients with acute respiratory distress syndrome (ARDS), based on indirect evidence.

- The panel made weak recommendations against use of corticosteroids in patients without ARDS, against use of convalescent plasma and against several antiviral drugs that have been suggested as potential treatments for COVID-19.

- Rigorous randomized trials are urgently needed to establish the benefits and risk of candidate interventions.

including use of widely adopted Grading of Recommendations Assessment, Development and Evaluation (GRADE) methodology for rating quality of evidence and grading strength of recommendations. ${ }^{7}$ Given the anticipated paucity of evidence from studies enrolling patients with COVID-19, the recommendations hinge on both direct and relevant indirect evidence. 


\section{Scope}

Health care providers represent the target audience of this guideline. The guideline includes 3 categories of interventions: corticosteroids, convalescent plasma therapy and antiviral drugs. We address the use of these interventions for COVID-19 in patients with nonsevere disease, severe disease and, for corticosteroids, those with ARDS, as the balance of benefits may differ among these groups. For instance, the death rate in patients with nonsevere COVID-19 is estimated to be $1 / 1000$ and in those with severe disease is estimated at more than $100 / 1000$, thus providing much more scope for important benefit in severe COVID-19. ${ }^{1}$

Our definition of severe COVID-19 pneumonia follows that of the WHO: fever or suspected respiratory infection, plus 1 of the following: respiratory rate $>30$ breaths/min, severe respiratory distress, or arterial oxygen saturation measured by pulse oximeter $\left(\mathrm{SpO}_{2}\right) \leq 93 \%$ on room air. ${ }^{8}$ The WHO definition of "severe" includes patients admitted to hospital with pneumonia who can be managed on medical wards and are not critically ill. Best evidence suggests that about $85 \%$ of such patients will never progress to critical illness such as ARDS. ${ }^{1}$

Because we anticipate that clinicians are unlikely to consider the use of convalescent plasma in patients with nonsevere COVID-19, for this intervention we addressed only patients with severe COVID-19. Similarly, clinicians are unlikely to consider corticosteroids in patients with nonsevere infection; in addressing corticosteroids use, we therefore focused on patients with severe COVID-19 and those with ARDS.

\section{Recommendations}

Box 1 summarizes the recommendations. We made 1 weak recommendation in favour of a treatment (corticosteroids in severe COVID-19 with ARDS) and made weak recommendations against use of the other treatments included in this guideline.

\section{Box 1: Summary of recommendations}

We suggest using corticosteroids in patients with severe coronavirus disease 2019 (COVID-19) and acute respiratory distress syndrome (ARDS) (weak recommendation).

- The agent, dose and duration of corticosteroid varied in the relevant randomized controlled trials. Methylprednisolone $40 \mathrm{mg}$ intravenously for 10 days represents 1 reasonable regimen used by critical care clinicians on our panel.

We suggest not using corticosteroids in patients with severe COVID19 who do not have ARDS (weak recommendation).

- If clinicians choose to use corticosteroids in patients who do not have ARDS, lower doses of corticosteroids for short periods may reduce the likelihood of toxicity.

We suggest not using convalescent plasma in patients with severe COVID-19 (weak recommendation).

We suggest not using ribavirin, umifenovir, favipiravir, lopinavirritonavir, hydroxychloroquine, interferon- $\alpha$ and interferon- $\beta$ in patients with nonsevere COVID-19 (weak recommendation).

We suggest not using ribavirin, umifenovir, favipiravir, lopinavirritonavir, hydroxychloroquine, interferon- $\alpha$ and interferon- $\beta$ in patients with severe COVID-19 (weak recommendation).

\section{Corticosteroids}

We suggest using corticosteroids in patients with severe COVID-19 and ARDS (weak recommendation).

Comment: The agent, dose and duration of corticosteroid varied in the relevant randomized controlled trials (RCTS). Methylprednisolone $40 \mathrm{mg}$ intravenously for 10 days represents 1 reasonable regimen used by critical care clinicians on our panel.

\section{Direct evidence}

In 1 observational study ${ }^{3}$ of patients with severe COVID-19 and ARDS, the administration of methylprednisolone reduced the risk of death (adjusted hazard ratio [HR] 0.41, 95\% confidence interval [Cl] 0.20 to 0.83 ; very low-quality evidence) (Appendix 1, available at www.cmaj.ca/lookup/suppl/doi:10.1503/cmaj.200648/-/DC1). ${ }^{9}$

\section{Indirect evidence}

The biological rationale for administering corticosteroids in a variety of conditions causing ARDS - including viral infections, bacterial infections and noninfectious causes - is similar and relates to the effect of corticosteroids on the inflammatory cascade and subsequent alveolitis leading to respiratory compromise. Evidence from 851 patients with ARDS in 7 RCTs suggests that use of corticosteroids results in a reduction in mortality that, applied to patients with COVID-19, may reduce deaths by $17.3 \%$ (95\% Cl $-27.8 \%$ to $-4.3 \%$; low-quality evidence) (Appendix 1). ${ }^{9}$

Corticosteroids may reduce the duration of mechanical ventilation by more than 4 days (low-quality evidence), but we are very uncertain regarding the effect of corticosteroids on length of stay in the intensive care unit (ICU) and length of hospital stay (Appendix 1). ${ }^{9}$

Corticosteroids may increase serious hyperglycemia events by $8.1 \%$ (low-quality evidence), may have little or no effect on gastrointestinal bleeding and neuromuscular weakness (lowquality evidence), and probably have little or no effect on superinfection (moderate-quality evidence) (Appendix 1 ). ${ }^{9}$

\section{Rationale}

Use of corticosteroids in patients with severe COVID-19 and ARDS may result in a substantial reduction in mortality, a critical outcome. The harm of short-term use of corticosteroids is limited. Based on our inferences regarding patients' values and preferences, we made a weak recommendation in favour of corticosteroids.

We suggest not using corticosteroids in patients with severe COVID-19 who do not have ARDS (weak recommendation).

Comment: If clinicians choose to use corticosteroids in patients who do not have ARDS, lower doses of corticosteroids for short periods may reduce the likelihood of toxicity.

\section{Direct evidence}

Very low-quality evidence from 2 cohort studies ${ }^{10,11}$ that included 331 patients with severe COVID-19 raised the possibility that corticosteroids may increase mortality compared with no corticosteroids (HR 2.30, 95\% Cl 1.00 to 5.29); 1 of these studies ${ }^{11}$ is a preprint (Appendix 1). ${ }^{9}$ 


\section{Indirect evidence}

Very low-quality evidence from 6129 patients with severe acute respiratory syndrome (SARS) in 2 observational studies ${ }^{12,13}$ raises the possibility that corticosteroids may reduce mortality. Evidence from 290 patients with Middle East respiratory syndrome (MERS) in 1 observational study ${ }^{14}$ also suggests that corticosteroids may reduce mortality, but again the evidence is very low quality. Evidence from SARS and MERS provides very low-quality evidence that corticosteroids may delay clearance of coronavirus ribonucleic acid (RNA) (Appendix 1). ${ }^{9}$ Efforts should be made to study corticosteroids for viral pneumonia (as distinct from ARDS) in RCTs.

Very low-quality evidence from 8530 patients with influenza in 11 observational studies raises the possibility that corticosteroids may increase mortality. It remains possible that corticosteroids increase superinfection and the need for mechanical ventilation (very low-quality evidence) (Appendix 1). ${ }^{9}$

Very low-quality evidence from 2034 patients with communityacquired pneumonia in 13 RCTs raises the possibility that corticosteroids may reduce mortality. Corticosteroids may reduce the need for mechanical ventilation by $10.4 \%(95 \% \mathrm{Cl}-13.8 \%$ to $-4.3 \%$; low-quality evidence), while very low-quality evidence raises the possibility of reductions in length of ICU stay, length of hospital stay and duration of mechanical ventilation. Corticosteroids probably increase serious hyperglycemia events by $5.7 \%$ (0.18\% to $15.3 \%$; low-quality evidence) and may increase neuropsychiatric events and superinfection events (low-quality evidence). Corticosteroids may have little or no effect on gastrointestinal bleeding (low-quality evidence) (Appendix 1). ${ }^{9}$

\section{Rationale}

In patients with severe COVID-19 outside the ICU, any benefit of corticosteroids is less than in those with ARDS. The indirect evidence regarding mortality was very low quality and inconsistent among SARS, MERS, influenza and community-acquired pneumonia. Lowquality evidence suggests that corticosteroids, when used over the short term, have modest harm. In this context, when any benefit is very uncertain, our inferences regarding patient values and preferences dictate a weak recommendation against use of corticosteroids in patients with severe COVID-19 who do not have ARDS.

\section{Convalescent plasma}

We suggest not using convalescent plasma in patients with severe COVID-19 (weak recommendation).

\section{Indirect evidence}

Very low-quality evidence from 40 patients with SARS in 1 observational study ${ }^{15}$ raises the possibility that convalescent plasma may reduce mortality (Appendix 2, available at www.cmaj.ca/ lookup/suppl/doi:10.1503/cmaj.200648/-/DC1). ${ }^{16}$

Four RCTs ${ }^{17-20}$ that included 572 patients with influenza contributed to very low-quality evidence suggesting that convalescent plasma may have little to no effect on mortality, may have a small benefit in hastening recovery and may reduce length of hospital stay and duration of mechanical ventilation. Use of convalescent plasma may result in little or no difference in rate of serious adverse events $(-1.2 \%, 95 \% \mathrm{Cl}-3.5 \%$ to $2.3 \%$; low-quality evidence) (Appendix 2$){ }^{16}$

\section{Rationale}

Very low-quality evidence raised the possibility that convalescent plasma may have some benefit in important outcomes and may be safe. Given the resources associated with preparation and administration of convalescent plasma, we have insufficient evidence to support its use.

\section{Antiviral drugs}

We suggest not using ribavirin, umifenovir (Arbidol), favipiravir, lopinavir-ritonavir, hydroxychloroquine, interferon- $\alpha$ and interferon- $\beta$ in patients with nonsevere COVID-19 (weak recommendation).

Because the likelihood of death from COVID-19 in patients with nonsevere disease is extremely low (in the range of $1 / 1000$ ), we are very confident that antiviral drugs will have little or no effect on mortality in such patients. ${ }^{1}$

An $\mathrm{RCT}^{21}$ of umifenovir and lopinavir-ritonavir reported other relevant outcomes in patients with nonsevere COVID-19, including cough, fever and progression to severe disease, but the RCT included only a total of 23 patients treated with umifenovir and 28 patients treated with lopinavir-ritonavir; as a result, the confidence intervals were so wide as to make the evidence uninformative (Appendix 3, available at www.cmaj.ca/lookup/suppl/ doi:10.1503/cmaj.200648/-/DC1).22 One observational study ${ }^{23}$ in 120 patients with COVID-19 with mixed-severity disease provides very low-quality evidence that lopinavir-ritonavir may increase viral clearance at day 23 (Appendix 3$)^{22}$

With respect to interferon- $\alpha$, an observational study ${ }^{24}$ in 70 patients with mixed-severity COVID-19 provides very low-quality evidence that the addition of interferon- $\alpha$ to umifenovir therapy may not affect time to viral clearance or length of hospital stay relative to umifenovir alone. There is no published evidence regarding benefit or harm of interferon- $\beta$ or ribavirin in patients with nonsevere COVID-19.

With regard to favipiravir, an $\mathrm{RCT}^{25}$ in 236 patients with mixedseverity COVID-19 suggested, in comparison with umifenovir, a possible higher incidence of recovery at day 7 , but because of risk of bias, imprecision and indirectness, the evidence was only very low quality (Appendix 3).22 One observational study ${ }^{26}$ in 80 patients with nonsevere COVID-19 provides very low-quality evidence that favipiravir may increase viral clearance at day 7 relative to lopinavir-ritonavir. Symptomatic benefit outcomes from patients with nonsevere disease for other agents were unavailable.

Turning to harms, studies of interferon- $\alpha$ did not address symptomatic harms. Observational studies suggested substantial increases in anemia (26\%) and bradycardia (15\%) with ribavirin, but whether patients experienced symptoms remains uncertain. ${ }^{27}$ Evidence regarding adverse effects in umifenovir is very low quality, and for favipiravir is low quality (Appendix 3 ). ${ }^{22} \mathrm{An} \mathrm{RCT}{ }^{28}$ of lopinavirritonavir provides moderate-quality evidence of increased diarrhea (6\%), nausea (9.5\%) and vomiting (6.3\%) with this drug combination.

Evidence for hydroxychloroquine came from $3 \mathrm{RCTs}^{29-31}$ of 240 patients with nonsevere COVID-19. Because of serious risk of bias (lack of blinding), imprecision (wide confidence intervals) and indirectness (both intervention and control groups included other drugs, limiting inferences regarding the effect of hydroxychloroquine), these studies provided very low-quality evidence 
regarding the following possible effects: little or no effect on viral clearance, a small reduction in duration of fever, little or no progression from nonsevere to severe disease, and little or no effect on recovery at day 7 (Appendix 3). ${ }^{22}$ Hydroxychloroquine may cause diarrhea in about $10 \%$ of patients (low-quality evidence). Very low-quality evidence suggests possible increases in headache, rash, nausea, vomiting and blurred vision (Appendix 3). ${ }^{22}$

\section{Rationale}

Because of a very low incidence of death, antiviral drugs cannot result in important mortality reductions in patients with nonsevere disease. We have no persuasive evidence of symptomatic benefit for any drug, with evidence of appreciable harm with ribavirin and lopinavir-ritonavir and high uncertainty regarding adverse effects in other drugs. Efforts should be made to study these agents in RCTs.

For all drugs to this point, the panel reached a consensus. For hydroxychloroquine, there was no suggestion of benefit in patients with nonsevere COVID-19, with possible increases in rash, nausea and vomiting. For hydroxychloroquine, 15 panel members voted for a weak recommendation against the drug, 3 voted for no recommendation, and 7 members had intellectual competing interests and did not vote.

We suggest not using ribavirin, umifenovir, favipiravir, lopinavirritonavir, hydroxychloroquine, interferon- $\alpha$ and interferon- $\beta$ in patients with severe COVID-19 (weak recommendation).

\section{Indirect evidence}

Observational studies ${ }^{12,32-34}$ of ribavirin and interferon in nonCOVID-19 coronaviruses (SARS and MERS) provide point estimates suggesting mortality reductions, but confidence intervals are very wide and include mortality increases; overall, the evidence is very low quality (Appendix 3 ). ${ }^{22}$ As presented in the previous section, an observational study ${ }^{27}$ suggests frequent anemia and bradycardia in patients receiving ribavirin, but the effect on patient experience remains uncertain.

\section{Direct evidence}

We have no direct evidence for ribavirin or interferon- $\beta$ in severe COVID-19 disease. For interferon- $\alpha$, as presented in the previous section, an observational study ${ }^{24}$ provides very low-quality evidence that the drug has minimal or no effect on time to viral clearance or length of hospital stay.

For umifenovir, the only $\mathrm{RCT}^{21}$ enrolled 23 patients with nonsevere COVID-19 disease, leaving (in addition to indirectness of evidence from patients with nonsevere disease) confidence intervals for all outcomes so wide as to be uninformative (Appendix 3).22 An observational study ${ }^{35}$ in 504 patients with mixed-severity COVID-19 provides very low-quality evidence that umifenovir may decrease mortality.

For favipiravir, we noted in the previous section the very lowquality evidence of increased viral clearance relative to lopinavirritonavir (Appendix 3). An $\mathrm{RCT}^{36}$ of lopinavir-ritonavir in 386 patients with influenza suggests the drug may not cause diarrhea (the results of this RCT have not yet been published).

Evidence from 199 patients with severe COVID-19 in $1 \mathrm{RCT}^{28}$ suggests that lopinavir-ritonavir may reduce mortality by $2.4 \%$
(95\% $\mathrm{Cl}-5.7 \%$ to $3.1 \%$ ), length of ICU stay by 5 days ( $95 \% \mathrm{Cl}-9$ to 0 ), and length of hospital stay by 1 day $(95 \% \mathrm{Cl}-2$ to 0$)$, but given the $95 \%$ confidence intervals, the results include the possibility of no effect (all low-quality evidence, from imprecision and risk of bias). We found moderate-quality evidence of increases in diarrhea (6\%), nausea $(9.5 \%)$ and vomiting (6.3\%) for lopinavir-ritonavir (Appendix 3). ${ }^{22}$ As presented in the previous section, 1 observational study ${ }^{23}$ in 120 patients with mixed-severity COVID-19 provides very low-quality evidence that lopinavir-ritonavir may increase viral clearance at day 23 (Appendix 3). ${ }^{22}$ Very low-quality evidence from 181 patients with severe COVID-19 and 255 patients with mixedseverity disease in 2 observational studies (preprints) ${ }^{37,38}$ raised the possibility that hydroxychloroquine may increase mortality and the need for mechanical ventilation (Appendix 3). ${ }^{22}$

\section{Rationale}

Very low-quality evidence raised the possibility that ribavirin, umifenovir, favipiravir, interferon- $\alpha$ and interferon- $\beta$ may have little or no benefit in mortality for patients with severe COVID-19. We are also very uncertain regarding the safety of these drugs in patients with severe disease.

The panel reached consensus on all recommendations regarding antiviral drugs mentioned thus far. As described above, however, for lopinavir-ritonavir, although $1 \mathrm{RCT}^{28}$ suggested the combination may reduce mortality, the $95 \% \mathrm{Cl}(-5.7 \%$ to $3.1 \%)$ included a $3.1 \%$ increase in mortality, and because of an open-label design, the study was at high risk of bias. Similarly, the $95 \% \mathrm{Cl}$ with respect to estimates of decreased length of ICU and hospital stay included no effect, and the evidence was overall low quality. Considering the uncertainty and the likely increases in diarrhea (best estimate $6 \%)$, nausea $(9.0 \%)$ and vomiting $(6.4 \%)$, the panel made a weak recommendation against the use of lopinavir-ritonavir. Ultimately, 14 panel members voted to recommend against the drug combination, and 6 were in favour; 5 members had intellectual competing interests and did not vote.

In patients with severe COVID-19, 2 observational studies ${ }^{37,38}$ raised the possibility that hydroxychloroquine may increase mortality and the need for mechanical ventilation. Ultimately, 15 panel members voted for a weak recommendation against the drug, 3 voted for no recommendation, and 7 members had intellectual competing interests and did not vote.

\section{Methods}

\section{Group composition and process}

The guideline steering committee comprised 5 members: the guideline chair (G.G.), the project lead (Z.Y.), a COVID-19 clinical investigator and clinical expert (B.D.), an academic pharmacist investigator (S.Z.) and a critical care physician and methodologist (B.R.). The main roles of the guideline steering committee included defining the scope of the guideline; proposing the initial specific clinical questions addressed by this guideline; choosing guideline panel members, including reviewing competing interests; determining the rules for reaching consensus or voting; overseeing the process of developing all affiliated systematic reviews and the summary of findings tables, and ensuring deadlines were met; and pro- 
posing the initial values and preferences that the panel ultimately endorsed for use in this guideline.

The guideline panel comprised 26 members from 6 countries (China, Canada, South Korea, Saudi Arabia, Singapore, Mexico) and included 6 critical care physicians, 5 pharmacists, 3 respiratory physicians, 1 infectious diseases physician, 1 nurse, 1 patient partner who had recovered from mild and 1 from severe COVID-19, and 8 methodologists, all of whom are also involved in clinical care (Appendix 4, available at www.cmaj.ca/ lookup/suppl/doi:10.1503/cmaj.200648/-/DC1, contains the full list of guideline panel members).

The guideline panel met 3 times by videoconference (Feb. 28, Mar. 23, and Mar. 24, 2020). Before the first meeting and between the first and second panel meetings, the steering committee also met to discuss issues of scope, population and approaches to summarizing indirect evidence, planning the systematic reviews and formulating recommendations.

Following these meetings, the panel continued with email correspondence; in particular, the panel reviewed a revised summary of findings table on hydroxychloroquine after our identification of new evidence in April 2020 and revoted on the corresponding recommendation on Apr. 25, 2020.

\section{Selection of priority questions}

At its first meeting, the guideline panel established the issues to be addressed in the guideline, based on the members' judgment of the questions of foremost concern to clinicians treating patients with nonsevere and severe COVID-19. The earlier section on "Scope" outlines the populations and interventions on which the panel chose to focus. The panel advised the systematic review teams on the priority outcomes of interest.

\section{Summarizing the evidence}

Following recommended methods, ${ }^{39}$ an independent group of systematic reviewers, with direction from the guideline steering committee and input from the panel, conducted 3 systematic reviews of the evidence relevant to our questions. ${ }^{9,16,22}$ These 3 systematic reviews ( 1 addressing corticosteroids, 1 on antiviral agents and 1 on convalescent plasma) included searches on MEDLINE, Embase, PubMed, Cochrane Central Register of Controlled Trials and medRxiv in March 2020 and applied no restriction on the language of publication. Additional details regarding the searches are available in the systematic reviews., 96,22 We included RCTs, cohort and case-control studies, but not single-arm studies. We also updated the direct evidence from COVID-19 to Apr. 25, 2020.

To assess risk of bias in RCTs, we used a modified version of the Cochrane 1.0 risk of bias instrument. ${ }^{40}$ To assess risk of bias in cohort and case-control studies, we used instruments developed by the CLARITY (Clinical Advances through Research and Information Translation) research group at McMaster University, Hamilton, Ontario. ${ }^{41,42}$

Using the GRADE approach, bodies of evidence were rated as high, moderate, low or very low quality. Randomized controlled trials began as high quality and observational studies as low quality. ${ }^{43}$ Issues of risk of bias, ${ }^{44}$ imprecision, ${ }^{45}$ inconsistency, ${ }^{46}$ indirectness ${ }^{47}$ and publication bias ${ }^{48}$ could lead to rating down of the quality of the study. The presence of a large magnitude of association or a dose-response gradient could lead to rating up of the quality of an observational study. ${ }^{49}$

We summarized evidence in GRADE summary of findings tables, presenting both relative and absolute effects. We obtained absolute effects by applying estimates of relative effects, sometimes from non-COVID-19 populations, to baseline risks that came from COVID-19 populations. In this document, because these are of most importance to patients, we present only absolute effects.

Because we anticipated a paucity of direct evidence from studies of patients with COVID-19, we summarized related indirect evidence from patients with SARS, MERS, ARDS, influenza, communityacquired pneumonia and, for adverse effects of convalescent plasma, Ebola virus disease. Using the GRADE approach, for efficacy outcomes from patients with SARS or MERS, we rated the evidence down 1 category for indirectness; for efficacy evidence from ARDS, influenza, community-acquired pneumonia and other acute viral infectious diseases, we rated the evidence down 2 categories for very indirect evidence. The panel considered evidence regarding adverse effects as less indirect than efficacy evidence and so rated the evidence down only once, or in some cases not at all, for indirect evidence.

\section{Values and preferences}

On the basis of the panel members' experience with patients, input from the 2 patient partners on the panel and knowledge of the limited available evidence, the panel specified the following value and preference judgments that were used to inform the recommendations. First, when modest harms were present and there was lowquality evidence of a small but important difference in an outcome important to patients (e.g., mortality), most patients would choose to receive an intervention. That is, most patients would place a higher value on an uncertain, small but important benefit than in avoiding modest harms. Second, when low-quality evidence suggests little or no benefit, or when only very low-quality evidence exists and effects are therefore very uncertain, most patients would decline the intervention.

\section{Formulation of recommendations}

The guideline panel developed the recommendations during the second and third guideline panel meetings and, as mentioned previously, for hydroxychloroquine during subsequent email correspondence. The panel had access to the summary of findings tables before the meetings, and the chair reviewed the details of the tables at the meetings. The recommendations were formulated at the meetings, after review of the evidence, based on magnitude of benefits and harms, quality of supporting evidence, and underlying values and preferences with, when relevant, some consideration of resource expenditure (Box 2).

The aim of the panel discussion was first to achieve consensus, which was successful for most recommendations. If the panel did not achieve consensus, a formal vote occurred, requiring $70 \%$ in favour of 1 option to make a recommendation. If the $70 \%$ threshold was not achieved, our process was to declare the panel undecided, make no recommendation, and instead report the vote and associated rationale. The chair endeavoured to guide the panel toward consensus without taking a position, and did not participate in the voting. 


\section{Box 2: Grading of recommendations}

The panel used the Grading of Recommendations Assessment, Development and Evaluation (GRADE) approach ${ }^{7}$ to inform the recommendations. It determined the strength of recommendations according to the balance between desirable and undesirable outcomes, with consideration of patient values and preferences, confidence in the estimates of effect and their associated uncertainty or variability, and resource use.

\section{Strong recommendations}

The panel made no strong recommendations.

\section{Weak recommendations}

The panel made exclusively weak recommendations based on the low or very low quality of the evidence, inferences regarding patient values and preferences and, secondarily, resources consumed by unproven interventions.

\section{Management of competing interests}

Our competing interest procedures adhered to Guidelines International Network principles. ${ }^{50}$ We collected both direct (financial) and indirect (intellectual) disclosures for all participants at the start of the guideline process and before publication. We excluded from the panel individuals with personal financial competing interests. Panel members completed a declaration of competing interests that steering committee members considered in making final decisions regarding conflicts, on a recommendation-by-recommendation basis (Appendix 5, available at www.cmaj.ca/lookup/suppl/doi:10.1503/cmaj.200648/-/ DC1). Members with intellectual conflicts, which included ongoing research addressing the treatments being considered, were permitted to participate in discussion but not in making decisions regarding recommendations for which they had competing interests.

Table 1 (part 1 of 2): International recommendations on the treatment of COVID-19

\begin{tabular}{|c|c|c|c|c|c|c|}
\hline Intervention & $\begin{array}{l}\text { IDSA guideline } \\
(\text { Apr. 21, 2020) }\end{array}$ & $\begin{array}{l}\text { SSC guideline } \\
(\text { Mar. 23, 2020) }\end{array}$ & $\begin{array}{l}\text { WHO interim } \\
\text { guidance } \\
\text { (Mar. 13, 2020) }^{8}\end{array}$ & $\begin{array}{l}\text { ANZICS guideline } \\
\text { (version 1, Mar. } \\
16,2020)^{53}\end{array}$ & $\begin{array}{l}\text { NICE guideline } \\
(\text { Apr. 3, 2020) }\end{array}$ & This guideline \\
\hline Corticosteroids ${ }^{*}$ & $\begin{array}{l}\text { Among patients who } \\
\text { have been admitted to } \\
\text { hospital with } \\
\text { COVID-19 pneumonia, } \\
\text { the IDSA guideline } \\
\text { panel suggests against } \\
\text { the use of } \\
\text { corticosteroids } \\
\text { (conditional } \\
\text { recommendation, } \\
\text { very low-certainty } \\
\text { evidence). }\end{array}$ & $\begin{array}{l}\text { In adults on } \\
\text { mechanical } \\
\text { ventilation with } \\
\text { COVID-19 and } \\
\text { respiratory failure } \\
\text { (without ARDS), the } \\
\text { SSC guideline } \\
\text { suggests against the } \\
\text { routine use of } \\
\text { systemic } \\
\text { corticosteroids } \\
\text { (weak } \\
\text { recommendation). } \\
\text { In adults on } \\
\text { mechanical } \\
\text { ventilation with } \\
\text { COVID-19 and ARDS, } \\
\text { the SSC guideline } \\
\text { suggests using } \\
\text { systemic } \\
\text { corticosteroids, over } \\
\text { not using } \\
\text { corticosteroids } \\
\text { (weak } \\
\text { recommendation). }\end{array}$ & $\begin{array}{l}\text { The WHO interim } \\
\text { guidance } \\
\text { recommends not } \\
\text { routinely giving } \\
\text { systemic } \\
\text { corticosteroids } \\
\text { for treatment of } \\
\text { viral pneumonia } \\
\text { outside clinical } \\
\text { trials. }\end{array}$ & $\begin{array}{l}\text { The ANZICS } \\
\text { guideline does not } \\
\text { recommend } \\
\text { corticosteroids for } \\
\text { routine use in } \\
\text { acute respiratory } \\
\text { failure with } \\
\text { COVID-19. Some } \\
\text { patients will have } \\
\text { appropriate } \\
\text { alternative clinical } \\
\text { indications for the } \\
\text { use of } \\
\text { corticosteroids, } \\
\text { such as the } \\
\text { presence of septic } \\
\text { shock. }\end{array}$ & $\begin{array}{l}\text { The NICE } \\
\text { guideline } \\
\text { recommends } \\
\text { not routinely } \\
\text { offering a } \\
\text { corticosteroid } \\
\text { unless the } \\
\text { patient has } \\
\text { other } \\
\text { conditions for } \\
\text { which these are } \\
\text { indicated, such } \\
\text { as asthma or } \\
\text { chronic } \\
\text { obstructive } \\
\text { pulmonary } \\
\text { disease. }\end{array}$ & $\begin{array}{l}\text { We suggest not } \\
\text { using } \\
\text { corticosteroids in } \\
\text { patients with } \\
\text { severe COVID-19 } \\
\text { who do not have } \\
\text { ARDS (weak } \\
\text { recommendation). }\end{array}$ \\
\hline $\begin{array}{l}\text { Convalescent } \\
\text { plasma* }\end{array}$ & $\begin{array}{l}\text { Among patients who } \\
\text { have been admitted } \\
\text { to hospital with } \\
\text { COVID-19, the IDSA } \\
\text { guideline panel } \\
\text { recommends } \\
\text { COVID-19 } \\
\text { convalescent plasma } \\
\text { in the context of a } \\
\text { clinical trial } \\
\text { (knowledge gap). }\end{array}$ & $\begin{array}{l}\text { In adults who are } \\
\text { critically ill with } \\
\text { coVID-19, the SSC } \\
\text { guideline suggests } \\
\text { against the routine } \\
\text { use of convalescent } \\
\text { plasma (weak } \\
\text { recommendation). }\end{array}$ & NR & NR & NR & $\begin{array}{l}\text { We suggest not } \\
\text { using convalescent } \\
\text { plasma in patients } \\
\text { with severe } \\
\text { CovID-19 (weak } \\
\text { recommendation). }\end{array}$ \\
\hline
\end{tabular}


Table 1 (part 2 of 2): International recommendations on the treatment of COVID-19

\begin{tabular}{|c|c|c|c|c|c|c|}
\hline Intervention & $\begin{array}{l}\text { IDSA guideline } \\
(\text { Apr. 21, 2020) }\end{array}$ & $\begin{array}{l}\text { SSC guideline } \\
(\text { Mar. 23, 2020) }\end{array}$ & $\begin{array}{l}\text { WHO interim } \\
\text { guidance } \\
\text { (Mar. 13, 2020) }^{8}\end{array}$ & $\begin{array}{c}\text { ANZICS guideline } \\
\text { (version 1, Mar. } \\
16,2020)^{53}\end{array}$ & $\begin{array}{l}\text { NICE guideline } \\
(\text { Apr. 3, 2020) }\end{array}$ & This guideline \\
\hline \multicolumn{7}{|l|}{ Antiviral drugs } \\
\hline Umifenovir & NR & NR & NR & NR & NR & $\begin{array}{l}\text { We suggest not } \\
\text { using umifenovir in } \\
\text { patients with } \\
\text { nonsevere and } \\
\text { severe COVID-19 } \\
\text { (weak } \\
\text { recommendation). }\end{array}$ \\
\hline Favipiravir & NR & NR & NR & NR & NR & $\begin{array}{l}\text { We suggest not } \\
\text { using favipiravir in } \\
\text { patients with } \\
\text { nonsevere and } \\
\text { severe COVID-19 } \\
\text { (weak } \\
\text { recommendation). }\end{array}$ \\
\hline Hydroxychloroquine & $\begin{array}{l}\text { Among patients who } \\
\text { have been admitted to } \\
\text { hospital with COVID-19, } \\
\text { the IDSA guideline } \\
\text { panel recommends } \\
\text { hydroxychloroquine in } \\
\text { the context of a clinical } \\
\text { trial (knowledge gap). }\end{array}$ & $\begin{array}{l}\text { Insufficient evidence } \\
\text { to make a } \\
\text { recommendation }\end{array}$ & NR & NR & NR & $\begin{array}{l}\text { We suggest not } \\
\text { using } \\
\text { hydroxychloroquine } \\
\text { in patients with } \\
\text { nonsevere and } \\
\text { severe COVID-19 } \\
\text { (weak } \\
\text { recommendation). }\end{array}$ \\
\hline Interferon- $\alpha$ & NR & NR & NR & NR & NR & $\begin{array}{l}\text { We suggest not } \\
\text { using interferon- } \alpha \\
\text { in patients with } \\
\text { nonsevere and } \\
\text { severe COVID-19 } \\
\text { (weak } \\
\text { recommendation). }\end{array}$ \\
\hline Interferon- $\beta$ & NR & NR & NR & NR & NR & $\begin{array}{l}\text { We suggest not } \\
\text { using interferon- } \beta \\
\text { in patients with } \\
\text { nonsevere and } \\
\text { severe COVID-19 } \\
\text { (weak } \\
\text { recommendation). }\end{array}$ \\
\hline $\begin{array}{l}\text { Lopinavir- } \\
\text { ritonavir }\end{array}$ & $\begin{array}{l}\text { Among patients who } \\
\text { have been admitted to } \\
\text { hospital with COVID-19, } \\
\text { the IDSA guideline } \\
\text { panel recommends the } \\
\text { combination of } \\
\text { lopinavir-ritonavir only } \\
\text { in the context of a } \\
\text { clinical trial } \\
\text { (knowledge gap). }\end{array}$ & $\begin{array}{l}\text { In critically ill adults } \\
\text { with COVID-19, the } \\
\text { SSC guideline } \\
\text { suggests against the } \\
\text { routine use of } \\
\text { lopinavir-ritonavir } \\
\text { (weak } \\
\text { recommendation). }\end{array}$ & NR & NR & NR & $\begin{array}{l}\text { We suggest not } \\
\text { using lopinavir- } \\
\text { ritonavir in } \\
\text { patients with } \\
\text { nonsevere and } \\
\text { severe COVID-19 } \\
\text { (weak } \\
\text { recommendation). }\end{array}$ \\
\hline Ribavirin & NR & NR & NR & NR & NR & $\begin{array}{l}\text { We suggest not } \\
\text { using ribavirin in } \\
\text { patients with } \\
\text { nonsevere and } \\
\text { severe COVID-19 } \\
\text { (weak } \\
\text { recommendation). }\end{array}$ \\
\hline
\end{tabular}

Note: ANZICS = Australian and New Zealand Intensive Care Society, ARDS = acute respiratory distress syndrome, COVID-19= coronavirus disease 2019, IDSA = Infectious Diseases Society of America, NICE = National Institute for Health and Care Excellence, NR = not reported, SSC = Surviving Sepsis Campaign, WHO = World Health Organization .

*These interventions were not considered for use in patients with nonsevere COVID-19 in this guideline. 


\section{Implementation}

This guideline will be available in user-friendly and multilayered formats for clinicians and patients through MAGICapp (https:// app.magicapp.org/\#/guideline/EK6W0n). This will include interactive GRADE summary of findings tables and consultation decision aids to facilitate shared decision-making. The guideline will be updated on MAGICapp as new information becomes available.

Additionally, the participants in this guideline anticipate being part of a wider effort to produce new recommendations rapidly when higher-quality practice-confirming or practicechanging evidence from RCTs becomes available.

The recommendations in this guideline should discourage use of interventions for which there is very low-quality evidence, thus decreasing medical waste. However, misleading statements about and advocacy for use of medications for which we were unable to find robust evidence of benefit at this time present the major barriers to this guideline's implementation.

\section{Other guidelines}

Table 1 summarizes the recommendations addressing corticosteroids, convalescent plasma and antiviral drugs from 5 guidelines on COVID-19, from the Infectious Diseases Society of America (IDSA), ${ }^{51}$ Surviving Sepsis Campaign (SSC), ${ }^{52}$ WHO,${ }^{8}$ Australian and New Zealand Intensive Care Society (ANZICS) ${ }^{53}$ and UK National Institute for Health and Care Excellence (NICE). ${ }^{54}$

With respect to corticosteroids and ARDS, IDSA recommends use only in the clinical trial context; SSC suggests in favour; and WHO, ANZICS and NICE all recommend against. In patients without ARDS, all guidelines recommend against use of corticosteroids.

Regarding convalescent plasma, IDSA recommends its use only in the context of a clinical trial. The SSC and our guideline suggested not using convalescent plasma. Other guidelines did not address convalescent plasma.

The IDSA recommended use of lopinavir-ritonavir only in the context of a clinical trial, and SSC, like our guideline, suggested against using this drug. The other guidelines did not address lopinavir-ritonavir. The IDSA recommended use of hydroxychloroquine only in the context of a clinical trial, and SSC made no recommendation on hydroxychloroquine; the other guidelines did not address hydroxychloroquine. None of these guidelines addressed any of the other drugs for which our guideline made recommendations.

\section{Gaps in knowledge}

The benefits and, to a considerable extent, the harms, associated with the interventions addressed in this guideline remain very uncertain. Although RCT evidence is required for all agents considered, the more promising agents should likely receive higher priority.

Because of the most promising evidence of important benefits at present, we suggest conduct of large, methodologically sophisticated RCTs to address the effect of corticosteroids in patients with severe COVID-19 and particularly those with ARDS, and lopinavir-ritonavir and umifenovir in severe COVID-19. Hydroxychloroquine would be another candidate for further study, not because of current evidentiary support from human studies, but rather because of the results from preclinical studies and the attention the drug has received thus far.

A large number of RCTs are under way to assess interventions in COVID-19, including an important WHO-sponsored initiative, the SOLIDARITY trial. ${ }^{55}$

\section{Limitations}

At the time we determined the scope of the guideline, we decided not to include remdesivir because it was not licensed for use anywhere in the world and tocilizumab because there were no studies available regarding its use. Both drugs are now among those being considered for use in COVID-19 and our failure to address them constitutes a limitation of this guideline.

The composition of the guideline panel represents another limitation: our panel included more men than women, and panellists were mainly from China and Canada.

\section{Conclusion}

Given the largely very low-quality evidence regarding benefits of the treatments that the panel considered, and given the panel's inferences regarding patient values and preferences, the panel made almost exclusively weak recommendations against use of the interventions included in this guideline. The research community should interpret the weak recommendations that this guideline offers as a call to urgently undertake rigorous RCTs of the candidate interventions.

\section{References}

1. Guan WJ, Ni ZY, Hu Y, et al. Clinical characteristics of Coronavirus disease 2019 in China. N Engl J Med 2020 Feb. 28 [Epub ahead of print]. doi: 10.1056/ NEJMoa2002032.

2. Huang C, Wang Y, Li X, et al. Clinical features of patients infected with 2019 novel coronavirus in Wuhan, China. Lancet 2020;395:497-506.

3. Wu C, Chen X, Cai Y, et al. Risk factors associated with acute respiratory distress syndrome and death in patients with Coronavirus disease 2019 Pneumonia in Wuhan, China. JAMA Intern Med 2020 Mar. 13 [Epub ahead of print]. doi: 10.1001/ jamainternmed.2020.0994.

4. Coehn E, Bonifield J, Nigam M. Trump says this drug has "tremendous promise," but Fauci's not spending money on it. CNN 2020 Apr. 10. Available: www. cnn.com/2020/03/28/health/coronavirus-hydroxychloroquine-trial/index.html (accessed 2020 Apr. 26).

5. Kalil AC. Treating COVID-19-off-label drug use, compassionate use, and randomized clinical trials during pandemics. JAMA 2020 Mar. 24 [Epub ahead of print]. doi: 10.1001/jama.2020.4742.

6. Institute of Medicine (US) Committee on Standards for Developing Trustworthy Clinical Practice Guidelines; Graham R, Mancher M, Miller Wolman D, et al, editors. Clinical practice guidelines we can trust. Washington (D.C.): National Academy of Sciences; 2011.

7. Guyatt $\mathrm{GH}$, Oxman $\mathrm{AD}$, Vist GE, et al. GRADE: an emerging consensus on rating quality of evidence and strength of recommendations. BMJ 2008;336:924-6.

8. Clinical management of severe acute respiratory infection (SARI) when COVID-19 disease is suspected: interim guidance. Geneva: World Health Organization; 2020 Mar. 13. 
9. Ye Z, Wang Y, Colunga-Lozano L, et al. Efficacy and safety of corticosteroids in COVID-19: a systematic review and meta-analysis including summaries of indirect evidence from ARDS, SARS, MERS, influenza, and community acquired pneumonia. CMAJ 2020. In press.

10. Li X, Xu S, Yu M, et al. Risk factors for severity and mortality in adult COVID-19 inpatients in Wuhan. J Allergy Clin Immunol 2020 Apr. 12 [Epub ahead of print]. doi: 10.1016/j.jaci.2020.04.006. .

11. Lu X, Chen T, Wang Y, et al. Adjuvant corticosteroid therapy for critically ill patients with COVID-19. MedRxiv 2020 Apr. 7. doi: 10.1101/2020.04.07.20056390.

12. Lau EHY, Cowling BJ, Muller MP, et al. Effectiveness of ribavirin and corticosteroids for severe acute respiratory syndrome. Am J Med 2009;122:1150.e11-21.

13. Long $\mathrm{Y}, \mathrm{Xu} \mathrm{Y}$, Wang $\mathrm{B}$, et al. Clinical recommendations from an observational study on MERS: glucocorticoids was benefit in treating SARS patients. Int J Clin Exp Med 2016;9:8865-73.

14. Arabi YM, Mandourah Y, Al-Hameed F, et al. Corticosteroid therapy for critically ill patients with Middle East respiratory syndrome. Am J Respir Crit Care Med 2018;197:757-67.

15. Soo YO, Cheng Y, Wong R, et al. Retrospective comparison of convalescent plasma with continuing high-dose methylprednisolone treatment in SARS patients. Clin Microbiol Infect 2004;10:676-8.

16. Devasenapathy $\mathrm{N}, \mathrm{Ye} Z$, Loeb M, et al. Indirect evidence on efficacy and safety of convalescent plasma in severe COVID-19 patients: systematic review and meta-analysis. CMAJ 2020. In press.

17. Beigel JH, Aga E, Elie-Turenne MC, et al. Anti-influenza immune plasma for the treatment of patients with severe influenza A: a randomised, double-blind, phase 3 trial. Lancet Respir Med 2019;7:941-50.

18. Beigel JH, Tebas P, Elie-Turenne MC, et al. Immune plasma for the treatment of severe influenza: an open-label, multicentre, phase 2 randomised study. Lancet Respir Med 2017;5:500-11.

19. Davey RT, Fernandez-Cruz E, Markowitz N, et al. Anti-influenza hyperimmune intravenous immunoglobulin for adults with influenza A or B infection (FLU-IVIG): a double-blind, randomised, placebo-controlled trial. Lancet Respir Med 2019;7:951-63.

20. Hung IFN, To KKW, Lee CK, et al. Hyperimmune IV immunoglobulin treatment: a multicenter double-blind randomized controlled trial for patients with severe 2009 influenza A(H1N1) infection. Chest 2013;144:464-73.

21. Li Y, Xie Z, Lin W, et al. An exploratory randomized, controlled study on the efficacy and safety of lopinavir/ritonavir or arbidol treating adult patients hospitalized with mild/moderate COVID-19 (ELACOI). medRxiv 2020 Apr. 15. doi: 10.110/2020.03.19.2 0038984.

22. Liu W, Zhou P, Chen K, et al. Efficacy and safety of antiviral agents in COVID-19 patients: systematic review and meta-analysis. CMAJ 2020. In press.

23. Yan D, Liu X-y, Zhu Y-n, et al. Factors associated with prolonged viral shedding and impact of Lopinavir/Ritonavir treatment in patients with SARS-CoV-2 infection. medRxiv 2020 Mar. 30. doi: 10.1101/2020.03.22.20040832.

24. Zhou Q, Wei X-S, Xiang X, et al. Interferon-a2b treatment for COVID-19. medRxiv 2020 Apr. 10. doi: 10.1101/2020.04.06.20042580.

25. Chen C, Huang J, Cheng Z, et al. Favipiravir versus Arbidol for COVID-19: a randomized clinical trial. medRxiv 2020 Apr. 15. doi: 10.1101/2020.03.17.20037432.

26. Cai QX, Yang MH, Liu DJ, et al. Experimental treatment with favipiravir for COVID-19: an open-label control study. Engineering 2020 Mar. 18 doi: 10.1016/j. eng.2020.03.007.

27. Muller MP, Dresser L, Raboud J, et al. Adverse events associated with highdose ribavirin: evidence from the Toronto outbreak of severe acute respiratory syndrome. Pharmacotherapy 2007;27:494-503.

28. Cao B, Wang Y, Wen D, et al. A trial of lopinavir-ritonavir in adults hospitalized with severe COVID-19. N Engl J Med 2020 Mar. 18. doi: 10.1056/NEJMoa2001282. [Epub ahead of print].

29. Chen J, Liu D, Liu L, et al. A pilot study of hydroxychloroquine in treatment of patients with common coronavirus disease-19 (COVID-19). J Zhejiang Univ (Med Sci) 2020 Mar. 6. doi: 10.3785/j.issn.1008-9292.2020.03.03.

30. Chen Z, Hu J, Zhang Z, et al. Efficacy of hydroxychloroquine in patients with COVID-19: results of a randomized clinical trial. medRxiv 2020 Apr. 10. doi: 10.1101 /2020.03.22.20040758.
31. Tang W, Cao Z, Han M, et al. Hydroxychloroquine in patients with COVID-19: an open-label, randomized, controlled trial. medRxiv 2020 Apr. 14 doi: 10.1101/20 20.04.10.20060558.

32. Al Ghamdi M, Alghamdi KM, Ghandoora Y, et al. Treatment outcomes fo patients with Middle Eastern respiratory syndrome Coronavirus (MERS CoV) infection at a coronavirus referral center in the Kingdom of Saudi Arabia. BMC Infect Dis 2016;16:174.

33. Leong HN, Ang B, Earnest A, et al. Investigational use of ribavirin in the treatment of severe acute respiratory syndrome, Singapore, 2003. Trop Med Int Health 2004;9:923-7.

34. Shalhoub S, Farahat F, Al-Jiffri A, et al. IFN-alpha2a or IFN-beta1a in combination with ribavirin to treat Middle East respiratory syndrome coronavirus pneumonia: a retrospective study. J Antimicrob Chemother 2015;70:2129-32.

35. Liu Q, Fang X, Tian L, et al. The effect of arbidol hydrochloride on reducing mor tality of COVID-19 patients: a retrospective study of real-world date from three hospitals in Wuhan. medRxiv 2020 Apr. 17. doi: 10.1101/2020.04.11.20056523.

36. Dose-finding study of favipiravir in the treatment of uncomplicated influenza. ClinicalTrials.gov: NCT01068912; 2010. Available: www.clinicaltrials.gov/show/ NCT01068912 (accessed 2020 Mar. 28).

37. Mahevas M, Tran VT, Roumier M, et al. No evidence of clinical efficacy of hydroxychloroquine in patients hospitalized for COVID-19 infection with oxygen requirement: results of a study using routinely collected data to emulate a target trial. medRxiv 2020 Apr. 14. doi: 10.1101/2020.04.10.20060699.

38. Magagnoli J, Narendran S, Pereira F, et al. Outcomes of hydroxychloroquine usage in United States veterans hospitalized with Covid-19. medRxiv 2020 Apr. 23. doi: $10.1101 / 2020.04 .16 .20065920$.

39. Higgins JPT, Thomas J, editors. Cochrane handbook for systematic reviews of interventions version 6.0. Oxford (UK): The Cochrane Collaboration; updated July 2019.

40. Guyatt GH, Busse JW. Modification of Cochrane tool to assess risk of bias in randomized trials. Ottawa: Evidence Partners. Available: www.evidencepartners. com/resources/methodological-resources/ (accessed 2020 Apr. 26).

41. Busse JW, Guyatt GH. Tool to assess risk of bias in cohort studies. Ottawa: Evidence Partners. Available: www.evidencepartners.com/resources/methodological -resources/ (accessed 2020 Apr. 26).

42. Busse JW, Guyatt GH. Tool to assess risk of bias in case-control studies Ottawa: Evidence Partners. Available: www.evidencepartners.com/resources/ methodological-resources/ (accessed 2020 Apr. 26).

43. Balshem $\mathrm{H}$, Helfand M, Schunemann HJ, et al. GRADE guidelines: 3 . Rating the quality of evidence. J Clin Epidemiol 2011;64:401-6.

44. Guyatt GH, Oxman AD, Vist G, et al. GRADE guidelines: 4. rating the quality of evidence - study limitations (risk of bias). J Clin Epidemiol 2011;64:407-15.

45. Guyatt $\mathrm{GH}$, Oxman AD, Kunz R, et al. GRADE guidelines 6. rating the quality of evidence - imprecision. J Clin Epidemiol 2011;64:1283-93.

46. Guyatt GH, Oxman AD, Kunz R, et al. GRADE guidelines: 7. rating the quality of evidence - inconsistency. J Clin Epidemiol 2011;64:1294-302.

47. Guyatt GH, Oxman AD, Kunz R, et al. GRADE guidelines: 8. rating the quality of evidence - indirectness. J Clin Epidemiol 2011;64:1303-10.

48. Guyatt GH, Oxman AD, Montori V, et al. GRADE guidelines: 5. rating the quality of evidence - publication bias. J Clin Epidemiol 2011;64:1277-82

49. Guyatt $\mathrm{GH}$, Oxman AD, Sultan S, et al. GRADE guidelines: 9. rating up the quality of evidence. J Clin Epidemiol 2011;64:1311-6.

50. Schünemann HJ, Al-Ansary LA, Forland F, et al. Guidelines International Network: principles for disclosure of interests and management of conflicts in guidelines. Ann Intern Med 2015;163:548-53

51. Bhimraj A, Morgan RL, Shumaker AH, et al. Infectious Diseases Society of America Guidelines on the treatment and management of patients with COVID-19. Arlington (VA): Infectious Disease Society of America; 2020. Available: www. idsociety.org/practice-guideline/covid-19-guideline-treatment-and-management/ (accessed 2020 Apr. 26).

52. Alhazzani W, Møller MH, Arabi YM, et al. Surviving Sepsis Campaign: guidelines on the management of critically ill adults with coronavirus disease 2019 (COVID-19). Intensive Care Med 2020 Mar. 28 [Epub ahead of print]. doi: 10.1007/s00134-020-06022-5. 
53. COVID-19 guidelines version 1. Camberwell (AU): The Australian and New Zealand Intensive Care Society (ANZICS); 2020. Available: www.anzics.com.au/ coronavirus-guidelines/ (accessed 2020 Apr. 26).

54. COVID-19 rapid guideline: managing suspected or confirmed pneumonia in adults in the community. London (UK): National Institute for Health and Care Excellence; 2020. Available: www.nice.org.uk/guidance/ng165 (accessed 2020 Apr. 26).
55. Public health emergency SOLIDARITY trial of treatments for COVID-19 infection in hospitalized patients. ISRCTN Registry. ISRCTN83971151; 2020. Available: www.isrctn.com/ISRCTN83971151 (accessed 2020 Apr. 26).
Competing interests: Younsuck Koh, Bin Du and Yaseen Arabi report being authors of Surviving Sepsis Campaign: Guidelines on the Management of Critically IIl Adults With Coronavirus Disease 2019, which made 1 recommendation relevant to this guideline regarding corticosteroids in acute respiratory distress syndrome. Bin Du reports being the principal investigator of an ongoing prospective randomized controlled trial (RCT) examining the efficacy of corticosteroids in patients with moderate-tosevere coronavirus disease 2019 (COVID-19), which is funded by the research grant 2020YFC0841300 from the Ministry of Science and Technology of the People's Republic of China. Srinivas Murthy and Robert Fowler report being investigators in a trial, supported by a Canadian Institutes of Health Research (CIHR) grant, evaluating the effect of corticosteroids and antiviral drugs (hydroxychloroquine and lopinavirritonavir) in patients with COVID-19. Ning Shen reports being an investigator in a trial evaluating the effect of hydroxychloroquine in patients with COVID-19, funded by Peking University Health Science Center. Neill Adhikari reports being a co-investigator of a CIHR-funded grant of antivirals in hospitalized patients with COVID-19 and of a second CIHR-funded grant of a variety of treatments, including corticosteroids, in critically ill patients with COVID-19. Mark Loeb reports receiving a grant and personal fees from the World Health Organization (WHO) for contract work on influenza and antibiotic resistance; consulting fees and a grant from Seqirus for an RCT on influenza; personal fees as a member of the advisory board and non-financial support from Sanofi, for an in-kind vaccine for the influenza RCT; and consulting fees from Pfizer and Medicago. Dr. Loeb also reports being an investigator in a trial evaluating the effect of chloroquine-azithromycin in patients with COVID-19, funded by Ontario Ministry of Health, Bayer and Abbott. François Lamontagne and Bram Rochwerg report being investigators in a trial, supported by a CIHR grant, evaluating the effect of corticosteroids and antiviral drugs (hydroxychloroquine and lopinavir-ritonavir) in patients with COVID-19. No other competing interests were declared.

This article has been peer reviewed.

Affiliations: Department of Health Research Methods, Evidence and Impact Canada (Ye, Rochwerg, Guyatt, Colunga-Lozano) and of Medicine (Rochwerg), McMaster University, Hamilton, Ont.; Department of Pharmacy (Wang), Beijing Chaoyang Hospital, Capital Medical University, Beijing, China; Department of Medicine, Interdepartmental Division of Critical Care Medicine (Adhikari, Fowler), University of Toronto, Toronto, Ont.; Department of Critical Care Medicine and Sunnybrook Research Institute (Adhikari, Fowler), Sunnybrook Health Sciences Centre, Toronto, Ont.; Department of Pediatrics (Murthy), University of British Columbia, Vancouver, BC; Department of Medicine (Lamontagne), Université de Sherbrooke; Centre de recherche du CHUS de Sherbrooke (Lamontagne), Sherbrooke, Que.; Department of Critical Care Medicine (Qiu), Zhongda hospital, School of Medicine, Southeast University, Nanjing, China; Department of Pharmacy (Wei), the First Affiliated Hospital of Guangzhou University of Medical; Department of Critical Care Medicine (Sang), the First Affiliated Hospital of Guangzhou Medical University, Guangzhou Institute of Respiratory Health, Guangzhou, China; Department of Pathology and Molecular Medicine and Health Research Methods, Evidence, and Impact (Loeb), McMaster University, Hamilton, Ont.; Department of Respiratory and Critical Care Medicine (Shen),
Peking University Third Hospital, Beijing, China; Guangdong kuaiwen information technology co. LTD (Huang), Guanzhong, China; Kunshan Guanghui Precise Metal Co. Ltd. (Jiang), Kunshan, China; Intensive Care Department (Arabi), King Saud bin Abdulaziz University for Health Sciences, Saudi Arabia; Department of Clinical Medicine (Colunga-Lozano), Health Science Center, Universidad de Guadalajara, Guadalajara, Mexico; Department of Critical Care Medicine (Jiang), Xuanwu Hospital, Capital Medical School, Beijing, China; Department of Pulmonary and Critical Care Medicine (Koh), University of Ulsan College of Medicine, Seoul, South Korea; Department of Pharmacy (Liu), Tongji Hospital, Tongji Medical College, Huazhong University of Science and Technology, Wuhan, Hubei, China; Department of Pharmacy (Liu, Zhai), Peking University Third Hospital, Beijing, China; Fast and Chronic Programmes (Phua), Alexandra Hospital, National University Health System, Singapore; Department of Pharmacy, the First Affiliated Hospital of USTC, Division of Life Sciences and Medicine, University of Science and Technology of China, Hefei (Shen), Anhui, China; General Surgery Department (Huo), Peking University Third Hospital, Beijing, China; Medical Intensive Care Unit (Du), Peking Union Medical College Hospital, Beijing

Contributors: Zhikang Ye, Suodi Zhai, Bin Du, Bram Rochwerg and Gordon Guyatt contributed to the conception and design of the work. Zhikang Ye, Ying Wang, Bram Rochwerg, Haibo Qiu, Mark Loeb, Luis Colunga-Lozano, Bin Du, Fang Liu, Suodi Zhai and Gordon Guyatt contributed to the acquisition of data. Zhikang Ye, Ying Wang, François Lamontagne, Robert Fowler, Neill Adhikari, Li Jiang, Mark Loeb, Haibo Qiu, Li Wei, Ling Sang, Ning Shen, Minhua Huang, Yaseen Arabi, Younsuck Koh, Luis Colunga-Lozano, Dong Liu, Fang Liu, Jason Phua, Aizong Shen, Tianui Huo, Bin Du, Suodi Zhai and Gordon Guyatt contributed to the analysis and interpretation of data. All of the authors drafted the manuscript, revised it critically for important intellectual content, gave final approval of the version to be published and agreed to be accountable for all aspects of the work.

\section{Funding: None.}

Content license: This is an Open Access article distributed in accordance with the terms of the Creative Commons Attribution (CC BY NC 4.0) license, which permits users to use, reproduce, disseminate or display the article provided the original work is properly cited and that the reuse is restricted to non-commercial purposes (i.e. research or educational use). See: https://creativecommons.org/licenses/by-nc/4.0/

Acknowledgements: The authors thank Rachel J. Couban for her contribution in developing the optimal search strategies for the 3 systematic reviews that informed this guideline.

Disclaimer: The authors alone are responsible for the views expressed in this article and they do not necessarily represent the views, decisions or policies of the institutions with which they are affiliated.

Endorsements: Association of Medical Microbiology and Infectious Disease (AMMI) Canada, Canadian Critical Care Society, Centre for Effective Practice and the Chinese Pharmaceutical Association, Hospital Pharmacy Professional Committee

Correspondence to: Bin Du, dubin98@gmail.com; Suodi Zhai, zhaisuodi@163.com; Gordon Guyatt, guyatt@mcmaster.ca 